\title{
INTRODUCTION OF A PRACTICAL LESSON FOR THE EVALUATION OF CAROTENOIDS IN FRUITS AND VEGETABLES FOR MASTER STUDENTS
}

\author{
C. Guijarro-Real, M. Plazas, A. Rodríguez-Burruezo, J. Prohens, A. Fita \\ Universitat Politècnica de València, Instituto de Conservación y Mejora de la Agrodiversidad \\ Valenciana (COMAV) (SPAIN)
}

\begin{abstract}
Master studies provide post-graduate students with an advanced training for a career specialization. In Plant Science studies, practical lessons can become essential during the learning process. In fact, these lessons can be used as a tool for consolidating the knowledge acquired with the theoretical lessons. Moreover, during the practical lessons, students have the opportunity to apply this knowledge to real situations, and to identify and deal with real problems that can appear. Our Institute offers a Master in Plant Breeding in which the learning process through practical lessons is conceived as an essential complement for theoretical knowledge. The Master provides students with the competence of designing and performing breeding programs addressed to improve adaptation of plants to biotic and abiotic stresses, as well as to improve the nutritional and sensorial quality of crops. In plants, there are different families of molecules related to defense, adaptation and/or quality, thus the study of them is of great importance in many breeding programs. An example of compounds with high interest is the family of carotenoids. Carotenoids include a group of compounds with several functions in plants. Some carotenoids are accessory pigments for photosynthesis or precursors of the abscisic acid, offer protection against photooxidative damage, or confer color to flowers, fruits and coloured roots, among other functions. They are also bioactive compounds related to the preservation of human health. According to this combined interest of carotenoids for 1) improving health status and 2) improving tolerance of crops, we consider that future professionals in Plant Breeding would improve their skills by performing an appropriate analysis of these compounds. Thus, we propose the introduction of a new practical lesson in the mandatory subject "Instrumental Techniques" addressed to the evaluation of individual carotenoids by high performance liquid cromatography (HPLC). During the lesson, which will be completed in three sessions, students will perform all the steps for the analysis of carotenoids from different plant material: extraction, preparation of sample for the HPLC analysis, preparation of standards, and analysis of results. At the end of the lesson, students should be able to perform autonomous analyses of carotenoids, and to deal with real problems that can occur during the protocol. In summary, this practical lesson complements the advanced learning process of students and provides them with a specific competence for their future careers. Moreover, guidance during the use of the HPLC should provide students with a secondary specific competence that is the knowledge and application of this technique, which can be transferred to other molecules. Finally, the lesson can be adapted to other Plant related and Food Technology studies.
\end{abstract}

Keywords: $\beta$-Carotene, carotenoids, chlorophyll, lutein, Plant science studies, specific competence.

\section{INTRODUCTION}

Master studies are conceived as a complement to Bachelor studies, providing an advanced training for professional, academic and research specialization [1]. As in other fields of knowledge, successful career development in Plant Science requires that professionals have practical and situational knowledge, professional experience and judgement [2]. The reason of this requirement is that professionals often develop a great number of tasks in both field and laboratory. Thus, educational programs of Master studies in Plant Science should effort in covering this advanced, experimental training by means of practical lessons.

Practical lessons can be considered as an active learning tool, one way to enhance the learning process. Practical lessons allow students to clarify, question and consolidate the knowledge acquired during the theoretical lessons [3]. In addition, practical works contribute to the acquisition of transversal competences and skills. In the case of laboratory practices, these skills include problem solving, interpreting and following protocols, managing efficiently the resources available (including time), and working more effectively and safely, among others [4]. When practical lessons are 
addressed to professional training, more than theoretical demonstrating, they should reflect activities that may be required to future professionals during their careers [1]. Our Institute offers a Master in Plant Breeding focused on training future professionals specialized in the development of new crop varieties. Interest in developing new varieties may attend to the need of increasing resistance/tolerance to biotic and abiotic stresses, or enhancing crop quality (e.g., yield, content in nutraceutical molecules, organoleptic quality, etc.). Due to the effect that different molecules synthesized by plants have on resistance and quality aspects, its analysis can become an essential tool in many breeding programs. Thus, we conceive the experimental training of students as an essential point in our educational program. In this context, we propose in this paper the introduction of a new practical lesson in the mandatory subject "Instrumental Techniques" addressed to improve the specific competence of students in analytical techniques for biomolecules phenotyping. In particular, this lesson is focused in the specific measurement of individual carotenoids by high performance liquid chromatography (HPLC). Carotenoids are a family of secondary metabolites with different functions in plants, such as pigmentation of flowers and fruits, photosynthesis, or even protection of plants against oxidative and light-related damage [5]. In addition, some carotenoids are involved in maintaining human health, providing for example vision and skin protection, and cancer prevention [6]. Carotenoids can be found in free (e.g., leafy vegetables) or esterified (e.g., pepper fruits) form [7], the latter needing a saponification step for a proper analysis. For this reason, the design of this practical lesson considers two different protocols according to the matrix. Among the techniques that can be used for analysis of carotenoids, HPLC technique allows the separation and simultaneous identification and quantification of different carotenoids present in a matrix [8]. Moreover, HPLC technique can be used for studying large quantity of other molecules. Thus, using this high-throughput technology will help students in the acquisition of this specific competence as well.

We hypothesize that the introduction of this practical lesson may contribute to an improved learning process, helping to a better understanding of the theoretical knowledge acquired and also training future professionals in this technique. The aims of the lesson are that students 1) learn how to analyze the target molecules, and choose the proper protocol depending if they are free or esterified; 2) gain confidence in using the HPLC technique; and 3) train in the adaptation of protocols to particular cases and learn how to deal with problems that could occur.

\section{THE PRACTICAL LESSON}

The practical lesson is designed to be completed in seven hours, in the course of which students will perform all the steps needed for a proper extraction and analysis of individual carotenoids from different fruits and vegetables. Students work by pairs as strategy to enhance the learning process by mutual help [9], with active guidance by the instructor during all steps. As plant material, the instructor will provide samples of leafy vegetables and fruits selected for having great contents of carotenoids, e.g., spinach and pepper [10, 11]. Each pair performs the extraction and analysis of two different materials that require different extraction protocols, thus giving all students the opportunity to learn both of them.

At the beginning of the lesson, the instructor provides an outline of the lesson, with a scheme including the tasks that students must perform and the chronogram (Fig. 1). The instructor takes also some minutes to refresh the fundamental aspects of the carotenoids, previously studied in the theory classes, so students can have a better perspective of the need of using different extraction procedures. As part of an active learning process, the instructor should avoid the unilateral explanation, but instead ask for a participative explanation mainly provided by students and guided by the instructor. 
Day 1

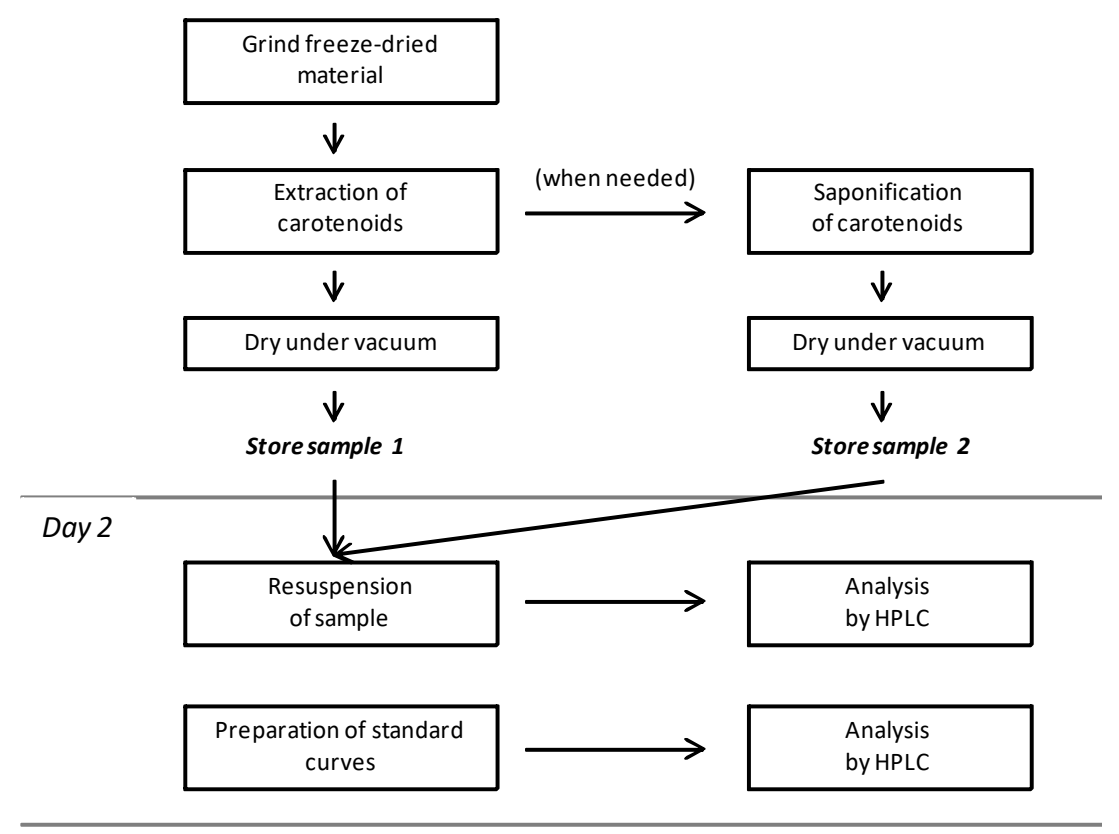

Day 3

$$
\begin{gathered}
\text { Analysis of results } \\
\text { and } \\
\text { key points for HPLC use }
\end{gathered}
$$

Figure 1. Scheme of the practical lesson.

\subsection{Session One}

The first session (three hours) is dedicated to the preparation and extraction of carotenoids from the material provided. The instructor initially provides the outline of the lesson and usefulness of the practice. In addition, the special security needs when managing the extraction solutions requires that the instructor explains as well the risks of the procedure, how to reduce them and the correct use of the facilities provided for that fact, and the actuation protocol in case of accident.

Once the key points are understood, students are asked to start with the extraction according to the following steps:

1 Grind the freeze-dried samples and weigh an adequate quantity of material, taking notes of the exact weight in each case.

2 Extract carotenoids from leafy material according to the protocol provided in the outline (Table 1). After extraction, samples must be given to the instructor for proceeding with drying - this task is explained to the students but should be performed by the instructor -.

3 Extract carotenoids from fruit material according to the protocol provided (Table 1). After extraction, samples must be given as well to the instructor for drying.

Table 1. Example of the extraction protocols that students are asked to follow.

\begin{tabular}{|l|l|}
\hline \multicolumn{2}{|c|}{ Extraction protocol for leafy material } \\
\hline 1. & Weigh $0.50 \mathrm{~g}$ of freeze-dried material. \\
\hline 2. & Add $25 \mathrm{~mL}$ of reagent alcohol, homogenize and sonicate for $5 \mathrm{~min}$. \\
\hline 3. & Centrifuge and transfer the supernatant to an adequate glass vial. \\
\hline 4. & Repeat steps $2-3$. \\
\hline 5. & Dry under vacuum, seal the vial and store at $-80^{\circ} \mathrm{C}$ until analysis. \\
\hline
\end{tabular}




\section{Extraction protocol for fruit material}

\begin{tabular}{|l|l|}
\hline 1. & Weigh $1.00 \mathrm{~g}$ of freeze-dried material. \\
\hline 2. & Add $15 \mathrm{~mL}$ of acetone:petroleum ether $(1: 1)$ solution, homogenize and sonicate for $5 \mathrm{~min}$. \\
\hline 3. & Centrifuge and transfer the supernatant to an adequate glass vial. \\
\hline 4. & Repeat steps $2-3$. \\
\hline 5. & Add $10 \mathrm{~mL}$ of $40.0 \% \mathrm{KOH}$ in $\mathrm{MeOH}$ and incubate for $30 \mathrm{~min}$ in continuous stirring. \\
\hline 6. & Centrifuge and transfer the supernatant to an adequate glass vial. \\
\hline 7. & Add $5 \mathrm{~mL}$ saturated $\mathrm{NaCl}$ plus $5 \mathrm{~mL}$ pure water and homogenize. \\
\hline 8. & Centrifuge and transfer the petroleum ether layer to an adequate glass vial. \\
\hline 9. & Dry under vacuum, seal the vial and store at $-80^{\circ} \mathrm{C}$ until analysis. \\
\hline
\end{tabular}

The extraction solutions that students need are prepared by the instructor prior to the session, in order to facilitate the correct development of the lesson. However, future professionals must be able to prepare these solutions if needed. Thus, during the incubation time, students are asked to calculate the quantity/volume of reagent/solvent needed for the correct preparation of the solutions used in the session.

The session should finish when the samples are completely dried, sealed and stored. However, drying solvents such as reagent alcohol can take several hours. Thus, the instructor will be the responsible of finishing the drying process of samples before use in the next session, in case that samples are not completely dried at the end of session one.

\subsection{Session Two}

The second session (two hours) is addressed to the preparation of samples for the analysis by HPLC. The tasks asked to the students during this session include:

1 Prepare the solvents needed for the HPLC apparatus. An adequate volume of each solvent will be prepared by students, considering the number of samples to be run. The students entrusted with the task must strictly follow the instructions provided in order to avoid accidents or health damage, working in fume hood and with adequate protection.

2 Prepare the samples for the HPLC analysis according to the protocols provided (Table 2).

3 Calculate and prepare the dilutions for the standard curves, preparing one curve per class for each carotenoid of interest.

4 Learn to start the HPLC analysis. The instructor shows how to program the HPLC, with particular interest in programming the calibration curves sequences.

At the end of this session, students should be able to start an analysis with HPLC, and also to prepare properly the calibration curves. The analysis needs several hours to be completed, so the apparatus will continue running after the session until finishing all injections.

Table 2. Example of the resuspension protocols that students are asked to follow.

\begin{tabular}{|c|l|}
\hline \multicolumn{2}{|c|}{ Resuspension protocol for leafy material } \\
\hline 1. & Add $2 \mathrm{~mL}$ of methanol. \\
\hline 2. & Sonicate for 20 min until complete resuspension. \\
\hline 3. & Centrifuge and filter the supernatant through a $0.22 \mu \mathrm{m}$ filter, in a compatible HPLC vial. \\
\hline \multicolumn{2}{|c|}{ Resuspension protocol for fruit material } \\
\hline 1. & Add $1 \mathrm{~mL}$ of ethyl acetate and stir gently. \\
\hline 2. & Add $1 \mathrm{~mL}$ methanol. \\
\hline 3. & Sonicate for 20 min until complete resuspension. \\
\hline 4. & Centrifuge and filter the supernatant through a $0.22 \mu \mathrm{m}$ filter, in a compatible HPLC vial. \\
\hline
\end{tabular}




\subsection{Session Three}

The last session ( 2 hours) is used for analyzing the results obtained. Results can be analyzed manually or obtaining the correspondent report generated by the software. Thus, students are initially asked to elaborate the calibration curves using the information obtained from the chromatograms (it is, manually) and provide the correspondent equations. These equations will be then used for obtaining the content in individual carotenoids in the crude materials. In addition, the instructor will show how to automatically elaborate the report using the HPLC software, as this tool can be very useful for future analyses that students may need to perform.

The rest of the session is used for teaching the key points for a successful carotenoid extraction and HPLC analysis. Thus, the instructor will discuss with students' real problems that students could need to deal with, and provide possible solutions. For example, they should discuss possible solutions for the adaptation of the extraction protocols to different materials that can vary in the content of carotenoids. They should also discuss possible solutions for increasing efficiency of HPLC analysis, and how to solve real problems that can appear as it would be the overlapping of different carotenoids of interest.

Finally, students are asked to fill a questionnaire used to evaluate the knowledge acquired (Table 3). It also includes some questions addressed to know how students perceive the learning process, which answers would be useful for a continuous improvement of the practical lesson.

Table 3. Example of the questionnaire for the evaluation of the practical lesson.

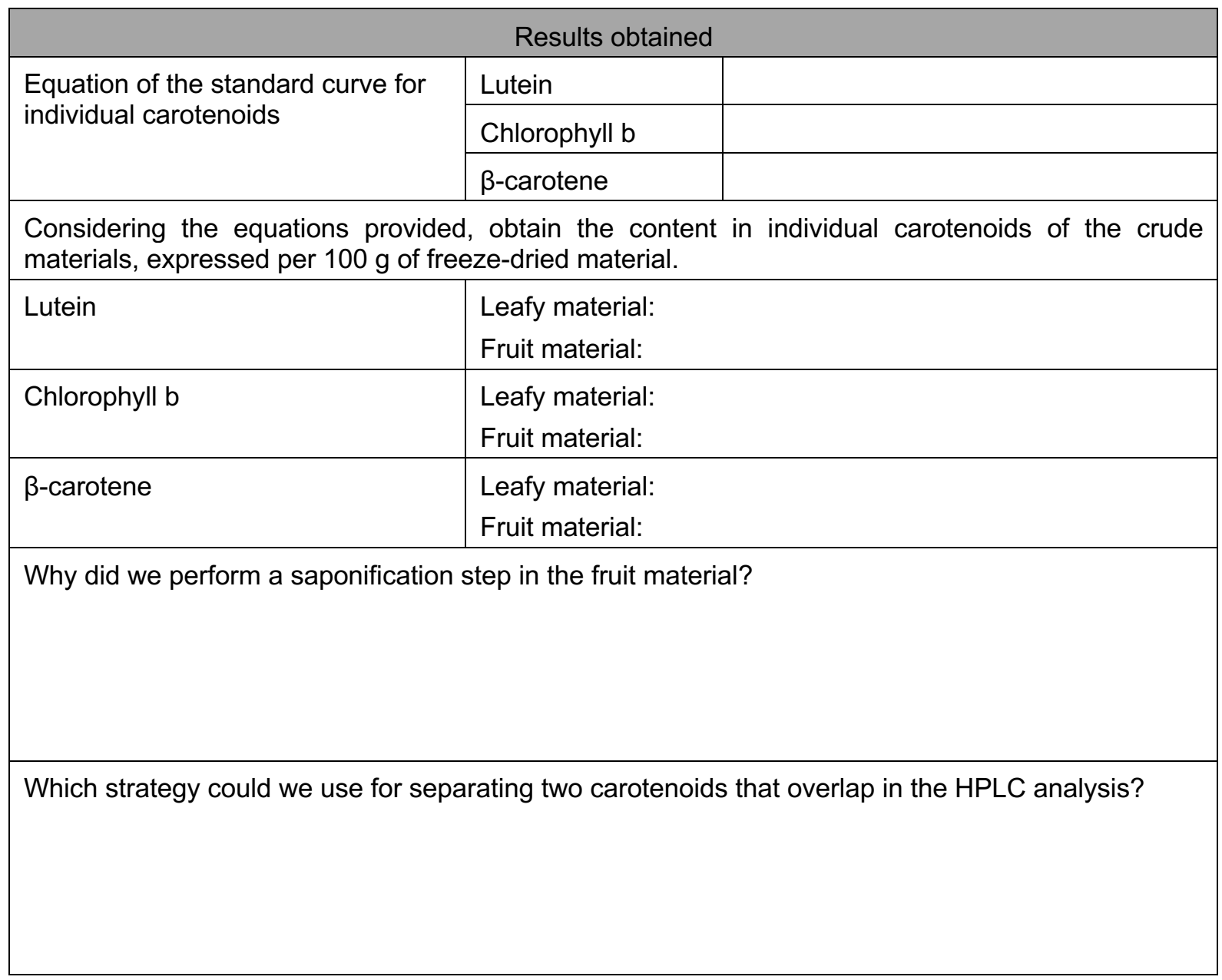




\begin{tabular}{|l|c|c|c|c|c|}
\hline \multicolumn{2}{|c|}{ Personal questionnaire } & \multicolumn{1}{|c|}{$\begin{array}{c}5 \\
\text { Totally } \\
\text { disagree }\end{array}$} & $\begin{array}{c}2 \\
\text { Disagree }\end{array}$ & $\begin{array}{c}\text { Not sure } \\
\text { Agree }\end{array}$ & $\begin{array}{c}\text { Totally } \\
\text { agree }\end{array}$ \\
\hline $\begin{array}{l}\text { The outline and explanations provided at } \\
\text { the beginning of the lesson are clearly } \\
\text { enough to understand the goal, } \\
\text { methodology and usefulness }\end{array}$ & & & & & \\
\hline $\begin{array}{l}\text { The explanations have been clear } \\
\text { enough to understand the lesson }\end{array}$ & & & & & \\
\hline $\begin{array}{l}\text { After the lesson, I think that I would be } \\
\text { able to perform autonomous analyses of } \\
\text { carotenoids }\end{array}$ & & & & & \\
\hline $\begin{array}{l}\text { After the lesson, I think that I would be } \\
\text { able to adapt the protocol to other } \\
\text { materials with greater/lower expected } \\
\text { content in carotenoids }\end{array}$ & & & & & \\
\hline $\begin{array}{l}\text { Comments related to the lesson } \\
\text { oomm }\end{array}$ & & & & & \\
\hline
\end{tabular}

\section{CONCLUSIONS}

The practical lesson should provide students with the specific competence of analyzing the content in individual carotenoids by HPLC in a great variety of food materials. Carotenoids are of great importance for plant survival and human health $[5,6]$, and can be enhanced by breeding programs. Thus, the acquisition of this specific competence contributes to an improvement in the profile of future professionals in this area.

By analyzing together leafy and fruit materials, the practical lesson provides a global vision in the analysis of carotenoids from different sources, which may need or not a saponification step [7]. In addition, using the HPLC procedure provides students with another specific competence that is the use of this methodology, which can be transferred to other molecules of interest. At the end of the lesson, students should be able to design an HPLC protocol suitable for the analysis of interest, to program the HPLC software and to generate adequate calibration curves. Moreover, they should be able to deal with real problems that can occur during the extraction and analysis procedures. Finally, the practical lesson could be adapted to other Plant Science studies as well as Food Technology studies, improving the competence of students in these fields as well.

\section{ACKNOWLEDGEMENTS}

Carla Guijarro-Real is grateful to the Ministerio de Educación, Cultura y Deporte of Spain for financial support by means of a predoctoral FPU grant (FPU14-06798). Mariola Plazas is grateful to Generalitat Valenciana and Fondo Social Europeo for financial support by means of a post-doctoral grant (APOSTD/2018/014).

\section{REFERENCES}

[1] A. Ismail, N.Z. Abiddin, A. Hassan, "Improving the development of postgraduates' research and supervision", International Education Studies, 4, pp. 78-89, 2011.

[2] N. Katajavouri, S. Lindblom-Ylänne, J. Hirvonen, "The significance of practical training in linking theoretical studies with practice", Higher Education, 51, pp. 439-464, 2006. 
[3] J. Wrenn, B. Wrenn, "Enhancing learning by integrating theory and practice", International Journal of Teaching and Learning in Higher Education, 21, pp. 258-265, 2009.

[4] University of Nottingham, "Studying effectively: Laboratory and practical lessons", accessed $2^{\text {nd }}$ May 2019. Retrieved from

https://www.nottingham.ac.uk/studyingeffectively/teaching/practicals/index.aspx

[5] A. Bartwal, R. Mall, P. Lohani, S.K. Guru, S. Arora, "Role of secondary metabolites and brassinosteroids in plant defense against environmental stresses", Journal of Plant Growth Regulation, 32, pp. 216-232, 2013.

[6] M. Eggersdorfer, A. Wyss, "Carotenoids in human nutrition and health", Archives of Biochemistry and Biophysics, 652, pp. 18-26, 2018.

[7] R.K. Saini, Y.S. Keum, "Carotenoid extraction methods: A review of recent developments", Food Chemistry, 240, pp. 90-103, 2018.

[8] J. Li, J. Xie, J. Yu, J. Zhang, X. Wang, C. Wang, C. Tang, Y. Zhang, M.M. Dawuda, D. Zhu, G. $\mathrm{Ma}$, "Reversed-phase high-performance liquid chromatography for the quantification and optimization for extracting 10 kinds of carotenoids in pepper (Capsicum annuum L.) leaves", Journal of the Agricultural and Food Chemistry, 65, pp. 8475-8488, 2017.

[9] D. Boud, "Introduction: making the move to peer learning" in Peer learning in higher education: learning from and with each other (D. Boud, R. Cohen and J. Sampson eds.), pp. 1-20, New York: Routledge, 2013.

[10] J. Corte-Real, C. Desmarchelier, P. Borel, E. Richling, L. Hoffmann, T. Bohn, "Magnesium affects spinach carotenoid bioaccessibility in vitro depending on intestinal bile and pancreatic enzyme concentrations", Food Chemistry, 239, pp. 751-759, 2018.

[11] B. Kirkhus, N. K. Afseth, G. I. A. Borge, S. Grimsby, C. Steppeler, A. Krona, M. Langton, "Increased release of carotenoids and delayed in vitro lipid digestion of high pressure homogenized tomato and pepper emulsions", Food Chemistry, 285, pp. 282-289, 2019. 